\title{
Remote Sensing of Sea Salt Aerosol below Trade Wind Clouds
}

\author{
Marcus Klingebiel,${ }^{a}$ Virendra P. GHAte, ${ }^{\mathrm{b}}$ ANN Kristin NAUMANN, ${ }^{\mathrm{a}}$ Florian Ditas, ${ }^{\mathrm{c}}$

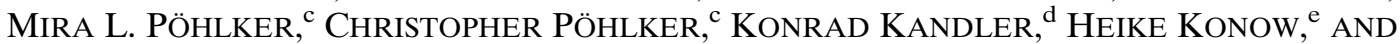 \\ BJORN STEVENS ${ }^{\mathrm{a}}$ \\ ${ }^{a}$ Max-Planck-Institut für Meteorologie, Hamburg, Germany \\ ${ }^{\mathrm{b}}$ Argonne National Laboratory, Argonne, Illinois \\ ${ }^{\mathrm{c}}$ Max-Planck-Institut für Chemie, Mainz, Germany \\ ${ }^{\mathrm{d}}$ Technische Universität Darmstadt, Darmstadt, Germany \\ ${ }^{\mathrm{e}}$ Universität Hamburg, Hamburg, Germany
}

(Manuscript received 17 May 2018, in final form 21 January 2019)

\begin{abstract}
Sea salt aerosol in the boundary layer below shallow cumulus clouds is remotely observed with a Ka-band cloud radar at the Barbados Cloud Observatory and is detected in $76 \%$ of the measurements over 1 year. Carried by convection, sea salt particles with a diameter larger than $500 \mathrm{~nm}$ show an upward motion of $0.2 \mathrm{~m} \mathrm{~s}^{-1}$ below shallow cumulus clouds for a 2-day case study. Caused by an increasing relative humidity with increasing altitude, the sea salt particles become larger as they move closer to the cloud base. By using combined measurements of a Ka-band cloud radar and a Raman lidar, the retrieved equivolumetric diameter of the hygroscopically grown sea salt particles is found to be between 6 and $11 \mu \mathrm{m}$ with a total number concentration of $20 \mathrm{~cm}^{-3}$ near cloud base. Assuming a fixed shape parameter, a size distribution of sea salt particles under high-relative-humidity conditions below cloud base is estimated and agrees with measurements taken by a dry-deposition sampler and online aerosol observations. The methods outlined in this paper can be used in future studies to get a better understanding of the vertical and temporal sea salt distribution in the boundary layer and sea salt aerosol-cloud interaction processes.
\end{abstract}

\section{Introduction}

Sea salt particles (dry and wet) are, next to mineral dust, the largest source of aerosol in the atmosphere (Satheesh and Moorthy 2005; O'Dowd and de Leeuw 2007) with a global flux of approximately $1-3 \times$ $10^{16} \mathrm{~g} \mathrm{yr}^{-1}$ (Erickson and Duce 1988). These common particles play an important role in Earth's radiation budget independently (Satheesh and Lubin 2003; Takemura et al. 2002) and through their influence on clouds. Furthermore, they serve as surfaces for heterogeneous chemical reactions (Quinn et al. 2015), thereby also affecting chemical cycles. Despite their potential importance to a range of processes, it has proven difficult to qualitatively constrain the role of sea salt in the climate system, in part because of the difficulty of characterizing its prevalence over the marine boundary layer.

Corresponding author: Marcus Klingebiel, marcus.klingebiel@ mpimet.mpg.de
Above the ocean, sea salt particles are always present, in amounts that depend strongly on the wind speed at the ocean surface, the sea surface temperature (Jaeglé et al. 2011), and the sea state. For wind speeds higher than $4 \mathrm{~m} \mathrm{~s}^{-1}$, whitecap formation at the ocean surface occurs and leads to a bubble-bursting process, which produces film and jet drops between $\sim 0.05$ and $\sim 32 \mu \mathrm{m}$ in dry diameter (Woodcock 1952; O'Dowd and de Leeuw 2007; Levin and Cotton 2009; Jensen and Nugent 2017). Nevertheless, the amount of sea salt particles in the atmosphere is also influenced by other factors, including precipitation, cloud processes, and mixing with the free troposphere.

Due to their high hygroscopicity, sea salt particles vary in size by a relative volume factor of up to 2.5 under different humidity conditions (Ault et al. 2013; Estillore et al. 2017), which makes them effective in interactions with water vapor and clouds. Therefore, sea salt particles in the atmosphere act as cloud condensation nuclei $(\mathrm{CCN})$ with a very high efficiency (Levin and Cotton 2009), and it is necessary to characterize the size and 
concentration of sea salt particles near cloud base to get a better understanding of their interaction with clouds.

By comparing the number of droplets in cumulus clouds over the sea with the number of $\mathrm{CCN}$ in the subcloud layer, Woodcock (1952) showed that sea salt particles may be important for rain formation processes. This agrees well with measurements from the Cloud, Aerosol, Radiation and Turbulence in the Trade Wind Regime over Barbados (CARRIBA) campaign, where Wex et al. (2016) speculate that sea salt, especially giant sea salt particles, could influence the formation of precipitation processes. The effect of giant $\mathrm{CCN}$ on the droplet size distribution and warm rain initiation is discussed in more detail by Johnson (1982), Rudich et al. (2002), and Posselt and Lohmann (2008) and largely motivated the Rain in Cumulus over the Ocean (RICO) field campaign (Rauber et al. 2007).

The interaction between sea salt aerosol and clouds is mainly observed by using aircraft-based in situ measurements. Remote sensing measurements of marine aerosol in the atmosphere are challenging because lidar instruments cannot directly differentiate between sea salt and other particles, and cloud radar instruments are usually not sensitive enough.

To study marine aerosol and their interaction with clouds, the island of Barbados provides a representative environment. It is located in the trade wind region of the Atlantic Ocean, approximately $150 \mathrm{~km}$ east of the islands that form the eastern boarder of the Caribbean Sea. The observed clouds in the vicinity of Barbados are representative of clouds across the trade wind regions (Stevens et al. 2016; Medeiros and Nuijens 2016). In this paper, we demonstrate that we can remotely sense marine aerosol at a cloud observatory located at Barbados to (i) quantify the presence of large sea salt particles in the boundary layer below shallow cumulus clouds and to (ii) estimate a sea salt size distribution in the subcloud layer by using a retrieval algorithm. These methods will be applicable for future studies to better understand the aerosol-cloud interaction and the dynamical structure of sea salt particles in the tropical subcloud layer.

\section{The Barbados Cloud Observatory}

The Barbados Cloud Observatory (BCO) is located on the windward coast of Barbados (Deebles Point; $13.16^{\circ} \mathrm{N}$, $59.43^{\circ} \mathrm{W}$ ) and is well situated to observe the air masses carried by the trade winds over the Atlantic Ocean (Stevens et al. 2016). Since 2010, the instruments have sampled the seasonal migration of the intertropical convergence zone (ITCZ) above this marine background site. Next to standard meteorological measurements (measuring, e.g., temperature, humidity, pressure, wind, rain rate, solar irradiance at $1-10$-s intervals), the key instruments for this study are introduced in the following subsections.

\section{a. Ka-band cloud radar}

The radar at the $\mathrm{BCO}$ (Fig. 1) is a 35.5-GHz (Ka band) polarized Doppler cloud radar with a sensitivity of $-48 \mathrm{dBZ}$ at an altitude of $5 \mathrm{~km}$ and $-70 \mathrm{dBZ}$ at an altitude of $500 \mathrm{~m}$. The radar has a range gating of $31.18 \mathrm{~m}$ and measures at ranges between 156 and $25972 \mathrm{~m}$. It is operated in a zenith-staring mode, so that range gating effectively measures distance in the vertical. An unusually large antenna endows it with a narrow beamwidth of $0.3^{\circ} \times 0.3^{\circ}$. The radar uses the Doppler technique with an FFT of 256 samples, giving it a Doppler resolution of $<0.02 \mathrm{~m} \mathrm{~s}^{-1}$ between -10 and $+10 \mathrm{~m} \mathrm{~s}^{-1}$. Following the procedures given in Görsdorf et al. (2015), with a pulsed magnetron and a co- and a cross-polarization receiver, the radar is able to provide the linear depolarization ratio (LDR), which is used for a target classification based on their shape (cloud droplets, insects, etc.). Data processing and radar calibration are also done by following Görsdorf et al. (2015), which leads to an uncertainty of $1.3 \mathrm{~dB}$ for the radar reflectivity measurements.

\section{b. Raman lidar}

The multichannel Raman lidar is used to routinely profile clouds, aerosol properties, and the temperature and humidity profiles in the atmosphere. A neodymiumdoped yttrium aluminum garnet (Nd:YAG) $10-\mathrm{Hz}$ laser with three wavelengths $(355,532$, and $1064 \mathrm{~nm})$ serves as a light source. Three telescopes with different ranges of overlap and different apertures are implemented to measure in the far range (overlap at $3000 \mathrm{~m}$ ), in the near range (overlap at $1000 \mathrm{~m}$ ), and in the close range (overlap at $200 \mathrm{~m}$ ). The measured parameters are particle backscatter as well as attenuated backscatter and extinction at wavelengths of 532 and $355 \mathrm{~nm}$. Based on counting statistics, uncertainty in extinction measurements is estimated to be less than $10 \%$. Furthermore, the Raman lidar is able to measure the volume and particle depolarization ratios at $532 \mathrm{~nm}$.

\section{c. Wind lidar}

A Streamline Pro Doppler lidar from HALO Photonics measures the vertical air motion below the cloud base. It is mounted on the roof of the radar container (Fig. 1) and measures vertical velocities up to $\pm 20 \mathrm{~m} \mathrm{~s}^{-1}$ at altitudes between 50 and $\sim 1000 \mathrm{~m}$ with an accuracy of $<20 \mathrm{~cm}^{-1}$ for a signal-to-noise ratio of $-17 \mathrm{~dB}$. The implemented laser has a pulse rate of $15 \mathrm{kHz}$, a 


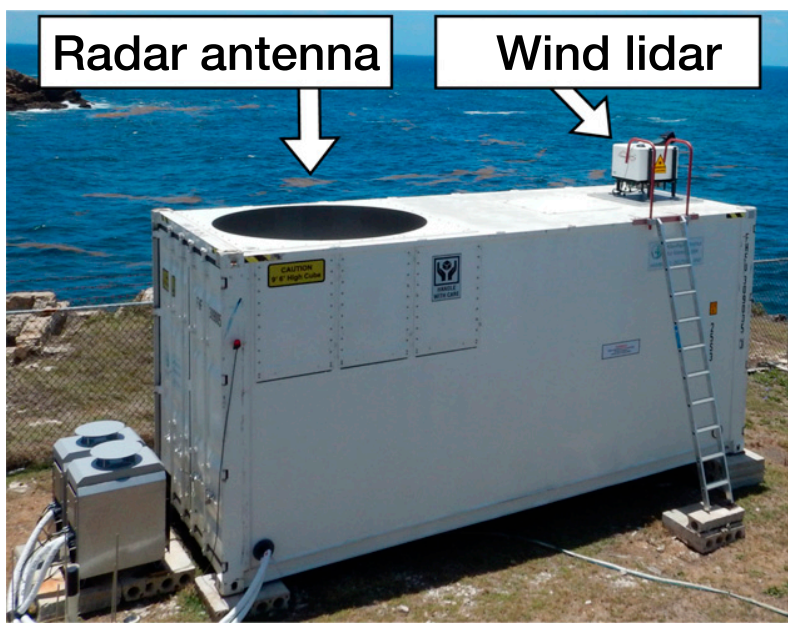

FIG. 1. The 35.5-GHz (Ka band) polarized Doppler cloud radar, located at the BCO. The container walls act as a clutter fence for the 2-m-diameter antenna dish. A wind lidar is mounted on the right side of the roof.

wavelength of $1500 \mathrm{~nm}$, and a typical divergence of less than $0.1 \mathrm{mrad}$ (O'Connor et al. 2010). To get adequate statistics of the fluctuations in the atmosphere, the temporal resolution is $1.3 \mathrm{~s}$.

\section{d. Aerosol measurements at Ragged Point}

At the Ragged Point research station (Prospero and Mayol-Bracero 2013; Prospero et al. 2014), $400 \mathrm{~m}$ north of the BCO across a small bay (Fig. 2 in Stevens et al. 2016), an optical particle sizer (OPS; model EDM 180, Grimm Aerosol Technik GmbH und Co. $\mathrm{KG}$, Ainring, Germany) measures the particle number and mass size distribution in the size range of 0.25-32 $\mu \mathrm{m}$ (optical particle diameter). The OPS illuminates single particles by means of a laser diode $(660 \mathrm{~nm})$; the detected scattered light is proportional to the particle size. The instrument is calibrated with spherical latex particles, a standard procedure allowing reasonable well particle sizing for atmospheric aerosol particles. The aerosol has been dried by using a Nafion dryer to keep the relative humidity below $40 \%$.

The OPS is hosted by an outdoor housing at the foundation of a 17-m-high measurement tower, whose base is itself $30 \mathrm{~m}$ above ground. The used aerosol inlet line is similar as that used by Wex et al. (2016). The aerosol enters the aerosol inlet at the top of the tower and is transported through a $9-\mathrm{m}$-long inlet tube $(0.2-\mathrm{m}$ diameter) under laminar flow conditions $\left(200 \mathrm{~L} \mathrm{~min}^{-1}\right)$ toward an isokinetic split that provides an aerosol flow $\left(1.2 \mathrm{~L} \mathrm{~min}^{-1}\right)$ to the OPS. The housing is located at a horizontal distance of only $2 \mathrm{~m}$ compared to the inlet on top of the tower, which is to minimize losses from sedimentation.
Individual particles are also sampled using a flat-platetype dry-deposition sampler (Ott and Peters 2008) on carbon adhesive at ambient conditions. The sampler is modified so that the collection surface in the lower-plate center is level with the lower plate, allowing for an undisturbed airflow between the plates. Sample collection time is approximately $24 \mathrm{~h}$ (1311 UTC 14 August1234 UTC 15 August 2016). The collected particles are analyzed by automated scanning electron microscopy with X-ray fluorescence analysis, yielding particle size and chemical composition for each particle (Kandler et al. 2011). Deposition rates were calculated from the number of particles, the analyzed area, and the sampling time. Based on the chemical composition, particles were classified into insoluble and soluble (or partly soluble) particles, that is, particles likely to have a spherical shape under ambient composition (Kandler et al. 2011).

\section{Observations}

Examining the high-sensitivity measurements from the improved Ka-band cloud radar reveals a weak radar reflectivity signal (between -50 and $-65 \mathrm{dBZ}$ ) near the top of the subcloud mixing layer, often below the cloud bases. We will show that this weak signal represents sea salt particles, which are presumable from bubble bursting at an agitated sea surface. The usually high-humidity conditions through the subcloud layer around Barbados $(>75 \%)$ make it easy for the sea salt particles to absorb water and grow hygroscopically with increasing altitude. In the following we will present two case studies to introduce the weak radar reflectivity signal of hygroscopically grown sea salt particles and their vertical motion inside the boundary layer. A statistical approach will demonstrate that this phenomenon occurs in threequarters of the measurements and correlates well with the near-surface observed particle number concentration and the near-surface observed horizontal wind speed, which is besides sea surface temperature and sea state an indicator for the amount of sea salt particles in the atmosphere.

\section{a. Case study 1: 9 March 2017}

Prior to July 2018, the Ka-band cloud radar has been set up to measure with a 10-s interval. Here, to better resolve the Doppler signal, we analyze a $90-$ min period from 9 March 2017, where the radar was configured with a 1-s integration time. As previous work (Acquistapace et al. 2017) has suggested, measurements with at least 2-s resolution are required to resolve the Doppler spectrum. This day is exemplary for typical days on Barbados, because shallow cumulus clouds, including the underlying weak radar 

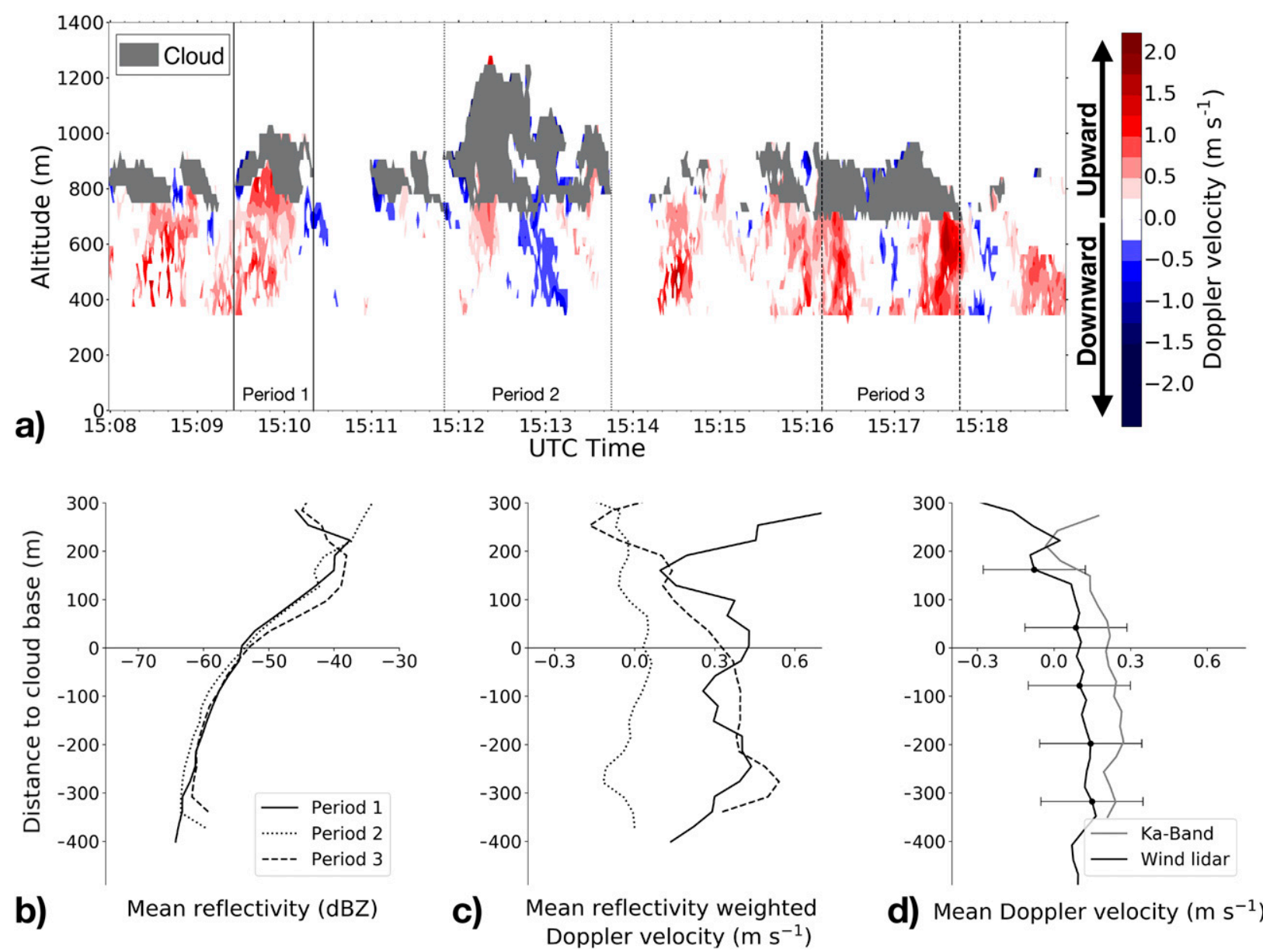

FIG. 2. (a) Doppler velocity measurements of the Ka-band cloud radar with a temporal resolution of 1 Hz on 9 Mar 2017. Clouds are marked in gray, and the color-coded scale indicates the Doppler velocity inside the haze echoes. Doppler velocities between -0.25 and $+0.25 \mathrm{~m} \mathrm{~s}^{-1}$ are removed. (b) Mean radar reflectivity of the three time periods marked in (a). (c) Mean reflectivityweighted Doppler velocity profiles. (d) Vertical velocity, averaged over all three time periods, measured by the Ka-band cloud radar and the wind lidar.

reflectivity signals, are present. Figure 2 a shows $11 \mathrm{~min}$ of radar measurements from this day. Reflectivity signals $>-50 \mathrm{~dB} Z$ are marked as cloud (gray) and the color-coded scale indicates the vertical Doppler velocity of the weak radar reflectivity signals $(-50$ to $-65 \mathrm{dBZ})$. Cloud-base height is taken as the lowest range gate with a signal $>-50 \mathrm{~dB} Z$ for each cloud period. That a threshold of $-50 \mathrm{~dB} Z$ is appropriate to distinguish between clouds and the weak radar reflectivity signal below is confirmed by comparisons with surface-based estimates of the lifting condensation level and a ceilometer, which operates at $905-\mathrm{nm}$ wavelength and reports the aerosol backscatter along with the optical cloud-base height.

Measurements of vertical air velocity, which coincide with the weak radar reflectivity signal, give information as to its origin. Downward motion indicates precipitation and the particle's origin inside the clouds, whereas upward motion indicates an origin in the subcloud layer. Most of the time, the vertical velocities show an upward motion between 0 and $1.75 \mathrm{~m} \mathrm{~s}^{-1}$ (updraft speed minus sedimentation speed). Downward motions between 0 and $-1.5 \mathrm{~m} \mathrm{~s}^{-1}$ are visible at the cloud edges (e.g., 1510:20, 1511:00, and 1518:00 UTC) and around 1513:00 UTC. The prevailing upward motion at the location of the weak radar reflectivity signals below the cloud base seems to trace circulations, which were studied by LeMone and Pennell (1976) and described as "cloud roots," that is, the trace of the boundary layer thermals upon which clouds form. Inside the cloud roots from LeMone and Pennell (1976), the upward motion showed velocities up to $0.35 \mathrm{~m} \mathrm{~s}^{-1}$. In our study, although the upward motion in Fig. 2a bears analogy with the cloud roots, the weak radar reflectivity signals point to a different phenomenon, because they indicate the presence of particles (assumingly hygroscopically grown sea salt 

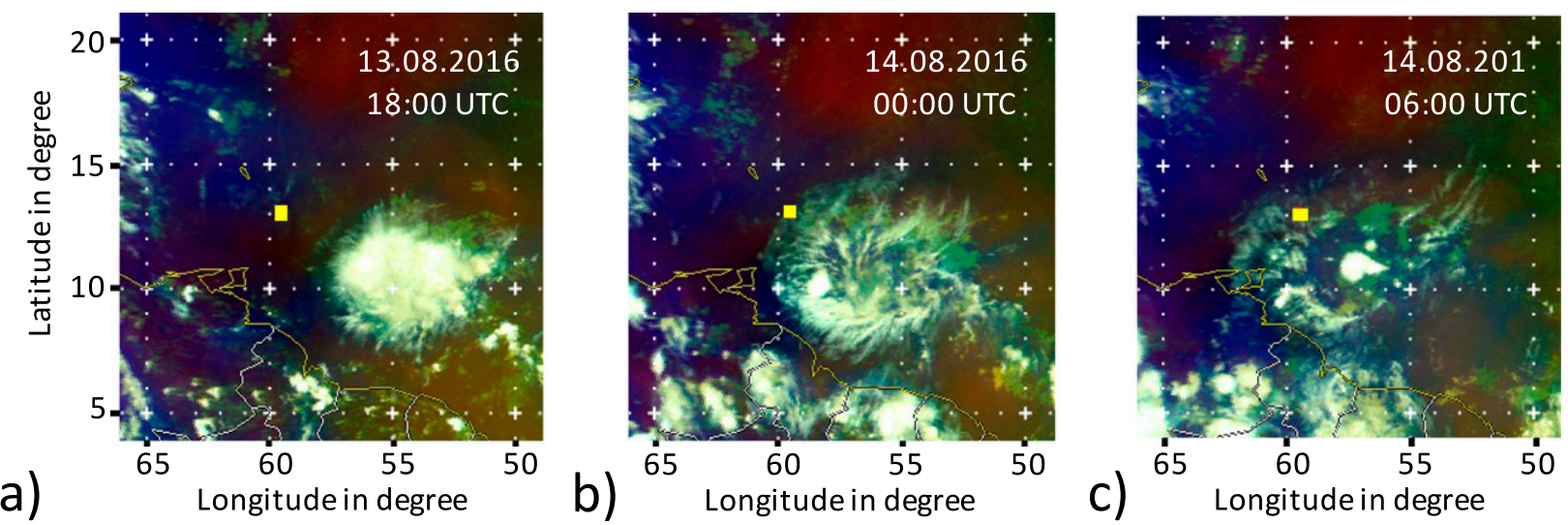

FIG. 3. Satellite images of the Meteosat RGB Air Mass Product by NOAA's National Hurricane Center show the development of a cloud system at different times. Barbados is marked by the yellow square, and the colors indicate the humidity of the air masses (red $=$ dry tropical air, green $=$ moist tropical air, blue $=$ midlatitude air $)$.

particles), which are carried upward by air motion (i.e., cloud roots). To be able to distinguish them from cloud roots, and because the observed weak radar reflectivity signals sometimes look like a haze forming in the subcloud layer, we denote the weak radar reflectivity signals as "haze echoes" in the following. Similar to the cloud roots, these features are not visible to the naked eye when below-cloud radar echoes are observed.

Vertical profiles of the haze echoes are calculated by averaging over time the reflectivity (Fig. $2 b$ ) and the reflectivity weighted Doppler velocity (Fig. 2c) for three different time periods, marked in Fig. 2a. For all three time periods, the mean reflectivity increases with increasing altitude toward the cloud base, which means that particles inside the haze echoes increase in size, assuming that the particle number concentration stays constant. Inside the cloud, the mean reflectivity increases further until it reaches a maximum, which is located in the upper part of each cloud (around $200 \mathrm{~m}$ above the cloud base for periods 1 and 2). The shapes of the mean weighted velocity profiles in Fig. 2c show mainly an upward motion. This indicates that the haze echoes occur mostly with updrafts.

To identify if other particles than hygroscopically grown sea salt show an upward motion as well, Fig. 2d shows the mean Doppler velocity from the radar in comparison to the mean Doppler velocity measured by the wind lidar. Both lines show the average of all three time periods. The gap between both profiles might be caused by the different detection methods of the instruments, for example, different fields of view. Even though the measurement principles and the detectable size ranges are different, both instruments show an upward motion inside the haze echoes, which indicates a surface origin of these particles and it supports the theory that sea salt particles injected from the sea surface cause this phenomenon. Considering only the measurements from the Ka-band radar, the mean upward velocity is approximately $0.2 \mathrm{~m} \mathrm{~s}^{-1}$ in this case study.

\section{b. Case study 2: 13 and 14 August 2016}

The previous subsection introduces the weak radar reflectivity signal below shallow cumulus clouds, which is denoted as haze echoes. This subsection shows the temporal evolution of the haze echoes under changing atmospheric conditions and uses the Raman lidar to test and refute the hypothesis that the signal is caused by a radar artifact.

On 13 August 2016, a deep convective cloud system developed approximately $600 \mathrm{~km}$ southeast of Barbados (Fig. 3a). Embedded in the tropical easterlies, it moved toward Barbados and reached the BCO around midnight (Fig. 3b). During 14 August 2016, more convective clouds systems developed near Barbados (Fig. 3c) and the island was under the influence of different types of clouds the entire day.

Figure 4a shows the radar reflectivity factor measured by the Ka-band radar for both 13 and 14 August 2016. On 13 August 2016, the radar detects shallow cumulus clouds distributed over the whole day. The occurrence of the incoming convective cloud system is visible at 0100 UTC 14 August 2016, starting with some precipitation. During the rest of the day, the haze echoes with a weak radar reflectivity signal $(-50$ to $-65 \mathrm{dBZ})$ are present below the cloud base.

To demonstrate the dominance of the haze echoes more clearly, Fig. $4 \mathrm{~b}$ shows a cloud mask applied to the radar data. This mask separates clouds (radar reflectivity factor $>-50 \mathrm{~dB} Z$ and positive vertical velocity), precipitation (radar reflectivity factor $>-50 \mathrm{~dB} Z$ and negative 
a)

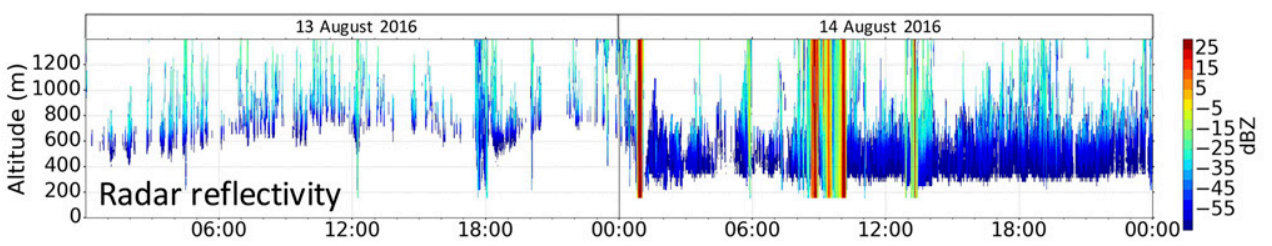

b)

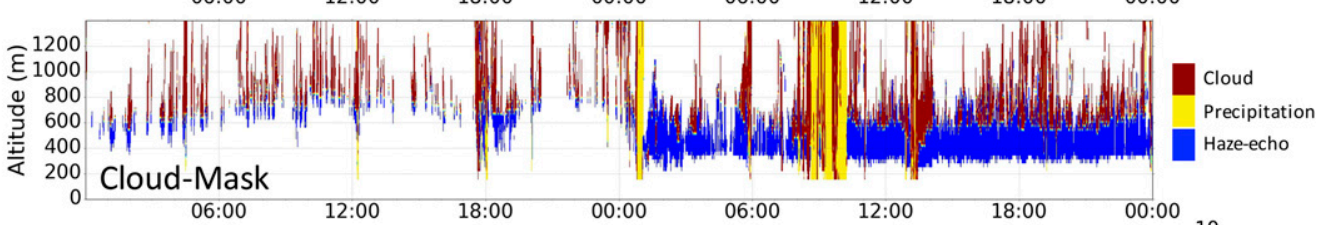

c)

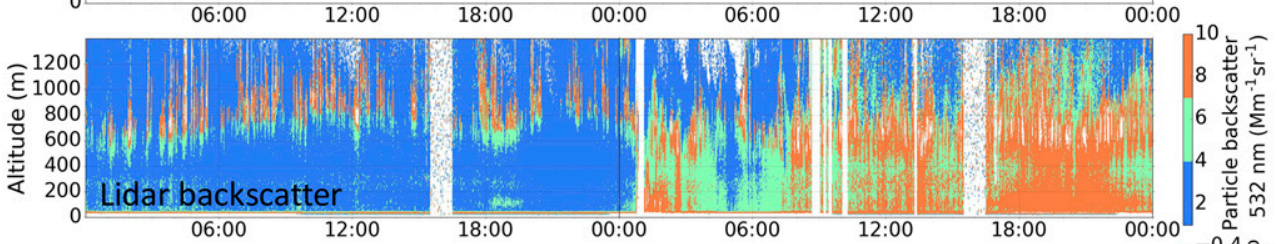

d)

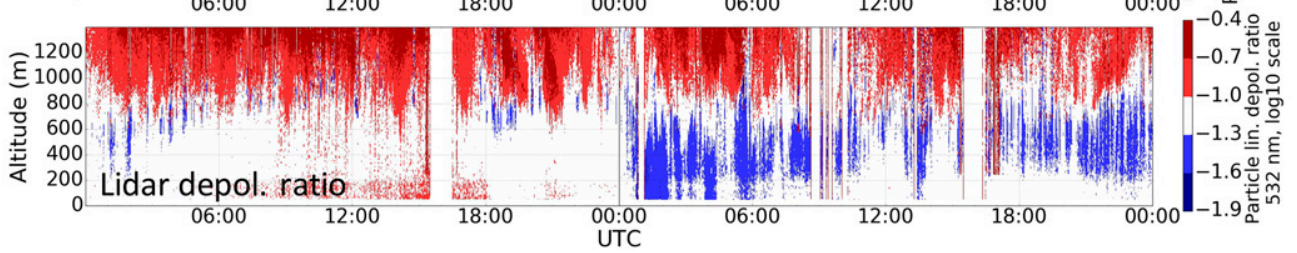

FIG. 4. Time series of measurements from 13 and 14 Aug 2016 at the BCO. (a) Ka-band cloud radar reflectivity, (b) cloud mask applied to the radar data, (c) particle backscatter from the Raman lidar, and (d) particle linear depolarization ratio from the Raman lidar.

vertical velocity), and the haze echoes (radar reflectivity factor $<-50 \mathrm{~dB} Z$ ).

Without considering data other than the radar reflectivity factor, these haze echoes could be anything (e.g., insects, aerosol, instrumental artifacts). To exclude the possibility that the haze echoes are artifacts caused by the radar instrument itself (e.g., Bragg scattering), we consult other measurements like the particle backscatter from the Raman lidar in Fig. 4c. On 14 August 2016, a higher particle backscatter is also visible below the cloud base than on 13 August 2016. This agrees well with the radar reflectivity signal (Fig. 4a) and demonstrates that the haze echoes are not only observable with the Ka-band cloud radar, which refutes the hypothesis that the haze echoes are caused by an instrumental artifact, for instance from a Bragg scattered signal.

To get information about the shape of the particles that form the haze echoes, the lidar particle linear depolarization ratio is given in Fig. 4d. The reddish color indicates a dust layer with aspherical particles above the clouds and a lidar particle linear depolarization ratio between -1.0 and -0.4 . However, spherical particles like cloud droplets appear with a lidar particle linear depolarization ratio between -1.9 and -1.3 . The regions where the haze echoes occur show values in the same range, which indicates that these particles have a more spherical shape.
Haze echoes with a radar reflectivity signal between -50 and $-65 \mathrm{~dB} Z$ are detectable by the Ka-band radar, these collocate with Raman-lidar signals with elected backscatter, but relatively small lidar particle linear depolarization signals, suggestive of a more spherical shape, so that the haze echoes coincide with elevated nondust backscatter signals, as one would expect from a sea salt source.

The occurrence of a haze echo in the Ka-band radar measurements is not a rare phenomenon. To estimate how often and how intensely a haze echo appears, we created a unitless haze-echo occurrence indicator. This indicator adopts values of one or zero for every measurement interval for altitudes up to $780 \mathrm{~m}$ (20 range gates) and counts the amount of range gates with radar reflectivity signals between -50 and $-65 \mathrm{dBZ}$. Figure 5a shows this haze-echo occurrence parameter for 13 and 14 August 2016, which are typical examples for days with a low and a high haze-echo occurrence, respectively. After looking at different days, we identified that a haze-echo occurrence threshold of 4 is a good proxy to discriminate between high and low intensities.

To analyze under which circumstances the haze echoes develop and what controls their intensity, it is important to consider other atmospheric parameters. For this reason, the temperature in combination with the 


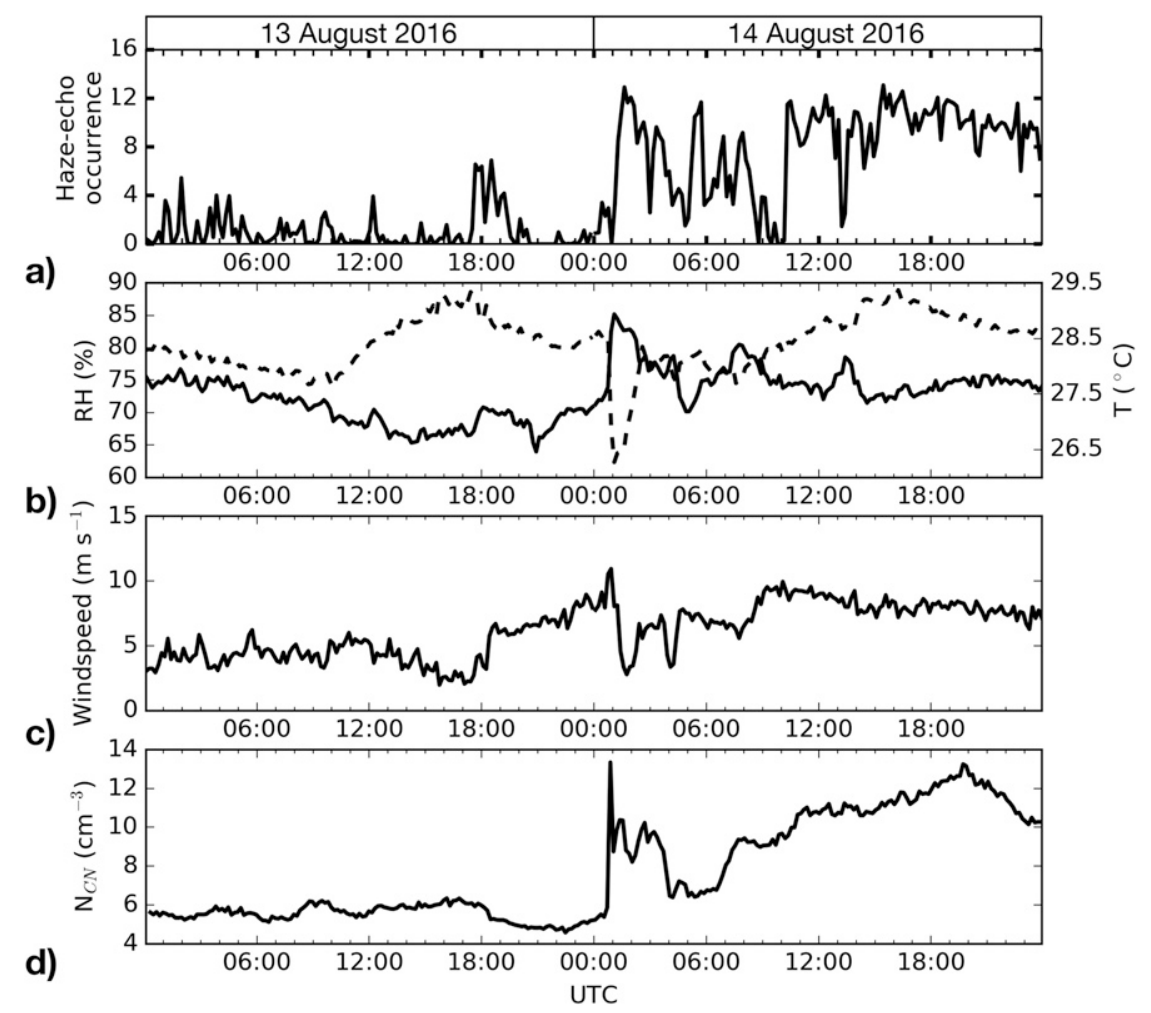

FIG. 5. (a) Calculated haze-echo occurrence, (b) temperature (dashed line) and the relative humidity (solid line), (c) horizontal wind speed, and (d) the OPS measurements for a particle diameter larger than $500 \mathrm{~nm}$ for 13 and 14 Aug 2016.

relative humidity and the wind speed are shown in Figs. $5 \mathrm{~b}$ and $5 \mathrm{c}$, respectively. The temperature follows a diurnal cycle with a maximum around 1700 UTC (1300 local time) on both days. A sudden drop in the temperature is visible at 0100 UTC 14 August 2016, which corresponds with the incipient precipitation. At the same time the surface relative humidity increases from $75 \%$ to $87 \%$. In general, the relative humidity at the surface is about $70 \%$ for $84 \%$ of the time, which is typical for the maritime tropics (Stevens et al. 2016). During the transition from 13 to 14 August 2016, the wind speed (see Fig. 5c) increases from around 4 to around $8 \mathrm{~m} \mathrm{~s}^{-1}$. This change in wind speed is associated with the incoming convective disturbance (see Fig. 3).

Figure $5 \mathrm{~d}$ shows particle number concentrations for particles larger than $500 \mathrm{~nm}$. There is a substantial covariability between the number concentration of this particle size fraction and the haze-echo occurrence (Fig. 5a), indicative of correlation. This leads to the assumption that particles, larger than $500 \mathrm{~nm}$, are involved in the development process of the haze echoes and it supports the sea salt hypothesis. Even if smaller sea salt particles are not associated with the haze echoes, they are also present in this region. A method to estimate the concentration of these smaller sea salt particles in the haze-echo region is proposed in section $4 b$.

\section{c. Statistical signature of haze echoes}

When only considering the 2-day dataset a clear correlation between meteorological instruments (wind, temperature, humidity) is hard to establish; however, the picture changes when looking at longer time scales. For this reason, we extended the analysis by using measurements for a year, from 1 July 2016 to 30 June 2017. Due to various instrument problems, only 313 days with data are available. For every available day, temperature, relative humidity, particle number concentration (measured by the OPS instrument), wind speed, and haze-echo occurrence are averaged over 6-h periods. This length ensures that the observed air mass is consistent and the statistical sample is large enough (Nuijens et al. 2009). To focus only on the dependence between haze echoes and the mentioned atmospheric parameters, we neglected periods inside the 6-h intervals, where no radar reflectivity signals or only precipitation (radar reflectivity factor $>-50 \mathrm{~dB} Z$ and negative vertical velocity) was present. The resulting 6-h averages of the haze-echo occurrence with respect to 

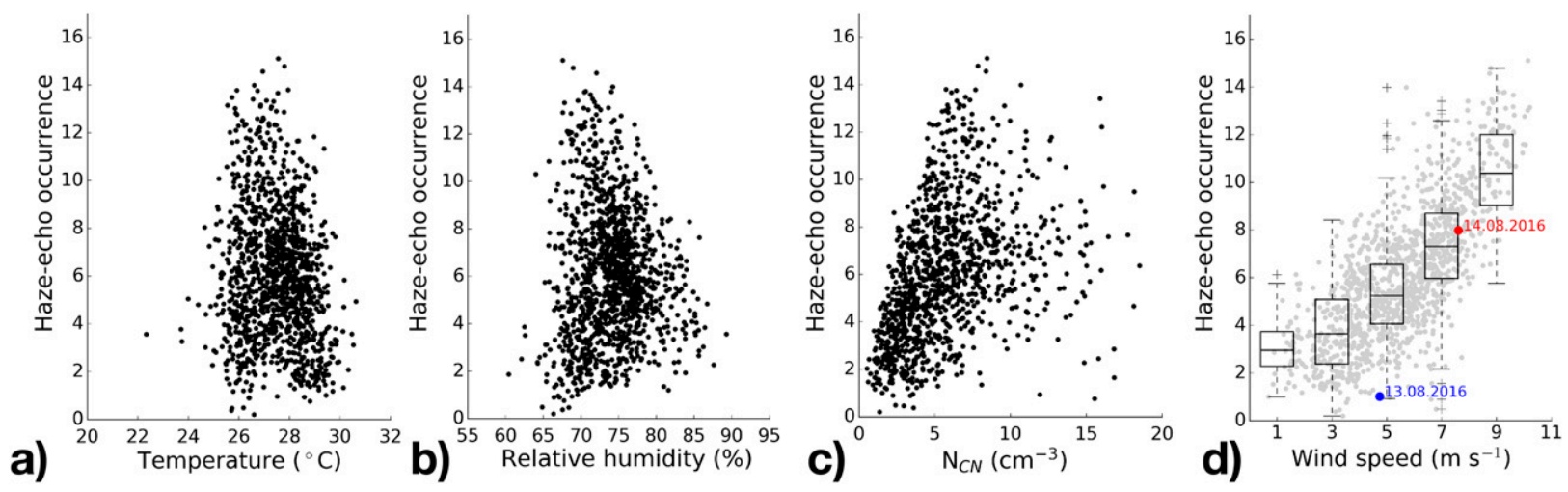

FIG. 6. Haze-echo occurrence with respect to (a) temperature, (b) relative humidity, (c) number concentration for particles larger than 500-nm diameter, and (d) wind speed. Every point represents an average of 6-h periods over 1 year of measurements (between 1 Jul 2016 and 30 Jun 2017). The box-and-whisker plots are added in (d) to show the spread as well as the median (horizontal line) of the data. The blue and red dots show averaged 6-h measurements for 13 and 14 Aug 2016, respectively.

temperature are shown in Fig. $6 a$. In $76 \%$ of the analyzed 6-h periods, the haze-echo occurrence is higher than 4 , which means that the haze echoes are clearly visible in the radar reflectivity measurements for these cases. Given the narrow temperature range on Barbados, a correlation between the haze-echo occurrence and the measured temperature cannot be found.

Figure $6 \mathrm{~b}$ compares the haze-echo occurrence and the relative humidity. Similar to the temperature, the relative humidity varies over the considered year and has a yearly mean value of $74 \%$, but shows again no clear correlation. By comparing the haze-echo occurrence with the OPS measurements for particles larger than 500-nm diameter, a correlation is apparent (Fig. 6c). Besides sea salt, the transatlantic transport of Saharan dust affects substantially the coarse mode abundance and compositions (Prospero and Mayol-Bracero 2013; Prospero et al. 2014; Weinzierl et al. 2017; Kandler et al. 2018). During the periods analyzed in this study, the dust abundance was relatively low, so we believe that most of the signal is from sea salt. However, considering that the OPS is not discriminating between sea salt and other aerosol species the correlation is expected to be moderate. Nevertheless, a clear trend emerges leading to the assumption that particles with a diameter larger than $500 \mathrm{~nm}$ occur more frequently with the haze echoes.

A distinct correlation between the haze-echo occurrence and the wind speed is also visible in Fig. 6d. With an increasing wind speed the haze-echo occurrence is increasing as well. This can be seen in the individual measurements (gray dots) as well as by looking at the median (horizontal line in the boxplots). A correlation between the haze-echo occurrence and the horizontal wind speed supports the theory that hygroscopically grown sea salt particles cause the haze echoes, because the amount of sea salt particles in the atmosphere is besides sea surface temperature and sea state strongly connected to the horizontal wind speed.

\section{Physically interpreting the haze-echo signal}

Section 3 introduces the haze echoes and shows in two case studies and one statistical approach that this phenomenon is consistent with the hypothesis that the signals originates from hygroscopically grown sea salt particles. This section elaborates this theory in further detail by retrieving a sea salt size distribution $100 \mathrm{~m}$ below cloud base. Furthermore, we explore, and refute, additional hypotheses for the origin of the haze echoes.

\section{a. Hygroscopically grown sea salt particles}

Sea salt particles are known to easily absorb water under subsaturated conditions (Tang et al. 1997). For a relative humidity higher than $75 \%$, the deliquescence point is reached and the particles adopt a spherical shape (Prather et al. 2013; Morris et al. 2016; Haarig et al. 2017). As observed by BCO ground measurements, the majority of the surface relative humidity measurements are around $74 \%$ (Fig. 6b). As air rises adiabatically from the surface to the cloud base, it cools and its relative humidity rises almost linearly to saturation at cloud base (Nuijens et al. 2015). Therefore, the humidity conditions between surface and cloud base on Barbados are always high enough to ensure that sea salt particles deliquesce. Given that the efflorescence relative humidity for sea salt of $43 \%$ is much lower than its deliquescence point, we expect all sea salt particles to be in a deliquesced state. In this state variations in the relative humidity control the size, but not the number, of the hygroscopically grown sea salt particles. For this reason, with increasing altitude the detected sea salt 
particles absorb more water and increase in size, which also leads to an increasing radar reflectivity factor with increasing altitude (Fig. 2b).

The number of sea salt particles in the atmosphere is mainly controlled by wind speed, sea surface temperature, and ocean state (Latham and Smith 1990; O'Dowd and de Leeuw 2007; Jaeglé et al. 2011). Wind leads to wave breaking and wave breaking causes bubble bursting at the sea surface with a subsequent injection of sea salt particles into the atmosphere: the higher the wind speed is, the more sea salt particles are injected into the atmosphere. This relationship matches well with observations at the BCO and Ragged Point, where the haze-echo occurrence and the number concentration of particles with a diameter greater than $500 \mathrm{~nm}$ show a correlation with the measured wind speed (see Figs. 5c,d). An exponential relationship between the horizontal wind speed and the haze-echo occurrence is given by the box-and-whisker plots in Fig. 6d. This agrees well with observations from Ovadnevaite et al. (2012), who found different exponential sea salt wind speed-concentration relationships for decreasing and increasing wind speeds up to $25 \mathrm{~m} \mathrm{~s}^{-1}$.

Moreover, because hygroscopically grown sea salt particles are carried by convective updrafts, they can be expected to become well mixed by turbulence through the subcloud layer. Turbulence in the subcloud layer also homogenizes its thermodynamic state (as measured by adiabatically invariant quantities such as potential temperature and specific humidity). This then leads to the relative humidity increasing with height through the subcloud layer, leading to the expectation that the deliquesced sea salt particles will increase with size as they experience higher humidities (Mordy 1959; Jensen and Nugent 2017), consistent with a weak, but increasingly pronounced, radar reflectivity signal at the top of the subcloud layer (see Fig. 2b). The haze echoes occur preferentially at the top of the subcloud layer, but tend to form more frequently under clouds, which is evident in Fig. 2. This is consistent with the relatively moistest air at any given level being associated with cloud roots (LeMone and Pennell 1976), as this is what then leads to cloud formation.

To further investigate the hypothesis that haze echoes are the signature of deliquesced sea salt particles, the size of the observed particles is estimated. This is done by using the Ka-band cloud radar and the Raman lidar $(532 \mathrm{~nm})$ to retrieve the microphysical properties inside the haze echoes. The retrieval method is based on the method of O'Connor et al. (2005), who assumed a gamma distribution and used the ratio of the radar backscatter power $Z$ to the lidar extinction coefficient $\alpha$ :

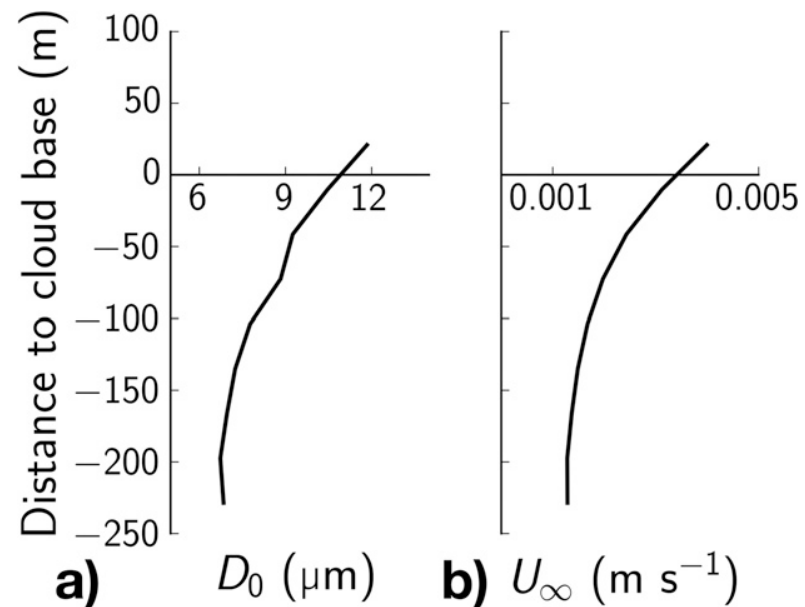

FIG. 7. (a) Equivolumetric droplet diameter $D_{0}$ and (b) the associated terminal velocity $U_{\infty}$ of the observed droplets, averaged between 1400 UTC and midnight 14 Aug 2016. The horizontal line marks the average cloud-base height.

$$
\frac{Z}{\alpha}=\frac{2}{\pi} \frac{\Gamma(7+\mu)}{\Gamma(3+\mu)} \frac{1}{(3.67+\mu)^{4}} D_{0}^{4} .
$$

This ratio is proportional to the fourth power of mean size, which can be used to estimate the median equivolumetric droplet diameter $D_{0}$. The shape of the assumed droplet size distribution is represented by the parameter $\mu$ and $\Gamma$ expresses the gamma function. For our studies we choose $\mu=0$, which is similar to O'Connor et al. (2005) and represents the well-known inverse-exponential distribution. Figure 7 a shows $D_{0}$ with respect to the altitude averaged over $10 \mathrm{~h}$ (from 1400 UTC to midnight) on 14 August 2016, when the haze echoes were present the entire day. Below the cloud base, the equivolumetric droplet diameter increases with increasing altitude from 6 to $11 \mu \mathrm{m}$. The droplets become bigger closer to the cloud base for reasons discussed above.

To test the theory that the droplets inside the haze echoes originate in the boundary layer and not inside the shallow cumulus clouds, we calculate the terminal velocity $U_{\infty}$ of a cloud droplet by following Pruppacher and Klett (2010). Figure $7 \mathrm{~b}$ shows the estimated terminal velocity for cloud droplets with diameters given in Fig. 7a. The terminal velocity confirms that it is very unlikely that the observed droplets below cloud base originate from inside the clouds. With a terminal velocity of less than $5 \times 10^{-3} \mathrm{~m} \mathrm{~s}^{-1}$, the fall speed of the cloud droplets is smaller than the typical upward motion in the subcloud layer. For this reason, cloud droplets cannot produce the weak radar reflectivity signals (i.e., the haze echoes) in an altitude of around $400 \mathrm{~m}$, because their size and fall speed are too small to overcome the 
upward motion. Next to the results of the vertical velocity measurements in case study 1 , these estimations appear to refute the idea that the haze echoes are a signal of precipitation or drizzle. Additionally, the lack of a signal near cloud edges (see Fig. 2a) seems to rule out the possibility that the particles are large droplets that linger in the detritus of a cumulus mixing event, as sometimes seen in simulations (Naumann and Seifert 2016).

\section{b. Retrieving a subcloud aerosol distribution}

In the following, we estimate a corresponding size distribution $100 \mathrm{~m}$ below the cloud base $(96 \%$ relative humidity) between 1400 UTC and midnight 14 August 2016 (same time period as in Fig. 7). To derive a size distribution from the retrieved equivolumetric droplet diameter $D_{0}$, we assume that the particles are gamma distributed, as described by the normalized gamma distribution (Testud et al. 2001):

$$
n(D)=N_{w} f(\mu)\left(\frac{D}{D_{0}}\right)^{\mu} \exp \left[\frac{-(3.67+\mu) D}{D_{0}}\right],
$$

with

$$
f(\mu)=\frac{6}{3.67^{4}} \frac{(3.67+\mu)^{4}}{\Gamma(\mu+4)} .
$$

Equation (2) describes a complete size distribution, where $n(D) d D$ defines the number concentration in the differential size interval between $D$ and $D+d D$ It has three free parameters, two of which can be constrained by the measurements. Here, starting with the retrieved value of $D_{0}$, and assuming a value of the shape parameter $\mu, Z=\int_{0}^{\infty} n(D) D^{6} d D$ is solved iteratively for the normalized concentration parameter $N_{W}$. This gives $N_{W}=9.83 \mathrm{~cm}^{-3}$ for $Z=-59.4 \mathrm{~dB} Z$ and $D_{0}=7.8 \mu \mathrm{m}$ (100 $\mathrm{m}$ below cloud base; see Fig. 7a). The result of the retrieved sea salt size distribution (given the assumed shape parameter $\mu$ ) can then be transformed into a normalized concentration $(d N / d \log D p)$.

The distributions estimated from this procedure are shown in Fig. 8 for two different values of the shape parameter and compare well to simultaneous measurements from the dry-deposition and particle (OPS) counter measurements. The dry-deposition sampler identified only $20 \%$ of the soluble particles as internally mixed with mineral dust, supporting the inference that most of the measured signal has a sea salt origin. For these soluble particles, growth factors and associated effective densities at ambient sampling conditions (73\% relative humidity) are calculated with the $\kappa-$ Köhler formulation (Petters and Kreidenweis 2007).

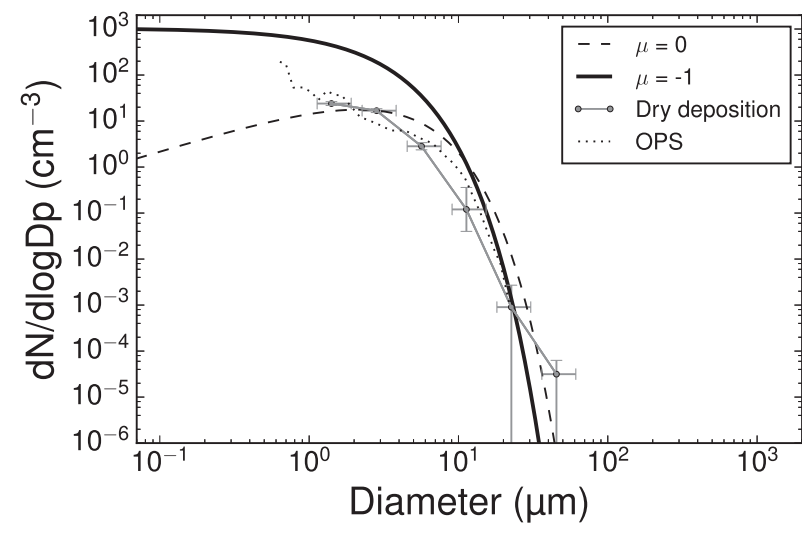

FIG. 8. Retrieved sea salt size distribution for different values of the shape parameter $\mu$ compared with OPS measurements and soluble particles, derived from dry-deposition measurements.

These values are subsequently used in a particle deposition model (Noll and Fang 1989)-including the ambient wind speed $\left(7.6 \mathrm{~m} \mathrm{~s}^{-1}\right)$ and the friction velocity estimated by the method of Wood (1981) for a flow over a smooth plate $\left(0.47 \mathrm{~m} \mathrm{~s}^{-1}\right)$ - to derive the ambient concentration of potential droplets. To model the droplet properties below the cloud, hygroscopic growth was calculated for a second time at $96 \%$ relative humidity, and finally droplet concentrations as a function of their size were determined. Figure 8 presents the final result, which shows a good agreement with the retrieved sea salt size distributions.

The OPS measurements (calculated assuming hygroscopic growth to $96 \%$ relative humidity using the $\kappa-$ Köhler theory with a hygroscopicity parameter $\kappa$ of 1 and a relative humidity of $40 \%$ in the OPS) show a similarly favorable agreement with the retrievals.

The retrievals are rather insensitive to the assumption of $\mu$ for $D>5 \mu \mathrm{m}$. Also in this size range the retrieved distributions agree best with the drydeposition measurements or as taken from the OPS. At smaller sizes the assumed value of the shape parameter plays a much larger role, suggesting that the remote sensing measurements do not directly constrain the number of $\mathrm{CCN}$. Taking $70 \mathrm{~nm}$ as the size cutoff for sea salt particles acting as $\mathrm{CCN}$, which corresponds to a supersaturation of $0.3 \%$, the sensitivity of the inferred $\mathrm{CCN}$ number concentration to the assumed value of $\mu$ can be quantified. For the case $\mu=-1$ the total number concentration is $1189 \mathrm{~cm}^{-3}$ for $D>70 \mathrm{~nm}$, as compared to $20 \mathrm{~cm}^{-3}$ for the case $\mu=0$. The number concentration for the OPS measurement is $36.5 \mathrm{~cm}^{-3}$, but only includes contributions from particles with $D>500 \mathrm{~nm}$. This exercise demonstrates that the remote sensing measurements might meaningfully constrain the number of giant 
CCN (here defined as $D>5 \mu \mathrm{m}$ ), but to constrain the minimum number of $\mathrm{CCN}$ from bubble bursting, an additional constraint on the size distribution is required. Nonetheless, our measurements indicate that this number is not inconsiderable, and that bubble bursting in the moderate and steady winds of the trades might be quite efficient at providing a robust source of cloud condensation nuclei in the maritime trades. This finding is consistent with a prior study from Lewis and Schwartz (2004).

\section{c. Other possibilities for causing haze echoes}

Although the prior results indicate that the haze echoes are most likely caused by hygroscopically grown sea salt particles and not by precipitation and drizzle processes, in this section we want to introduce and refute other hypotheses that could cause the haze echoes as well.

One hypothesis is that the weak radar reflectivity signals below the cloud base (haze echoes) are spurious, and simply arise from measurement noise. This can be excluded because the haze echoes are observed by two instruments, the Ka-band radar and the Raman lidar (Fig. 4), using different measurement principles.

The possibility that the signal is real but arises from insects or large dust particles is ruled out by the analysis of the radar signal, which uses the linear depolarization signal to filter weak signals (as these usually arise from spurious objects such as secondary echoes or signals from radar side lobes) and hence would not measure echoes from nonspherical particles. By using the Raman-lidar particle linear depolarization ratio, case study 2 also demonstrates that the particles inside the haze-echo region have a spherical shape. Furthermore, we identified a particle increase in size with height, caused by the change in relative humidity. We would not expect insects or dust particles to be as sensitive to relative humidity, and therefore the signal would be more uniformly distributed through the boundary layer in that case.

The possibility that the haze-echo signal could be from Bragg scattering processes associated with the sharp humidity gradients near cloud base was also considered. However, at the centimeter $(8.6 \mathrm{~mm})$ wavelength of the cloud radar, the Bragg scattering signal is much too weak to be observed (Gossard et al. 1984). Moreover, the structure of the signal, with large echoes well below the region of the maximum gradients and often directly under clouds where moisture gradients are expected to be weakest, is also inconsistent with the signal having arisen from Bragg scattering. This therefore suggests that the haze-echo signal is real and associated with spherical particles.
Another concern is that because the $\mathrm{BCO}$ is located very close to the surf zone of the island, its measurements might be unrepresentative of the conditions over the open ocean. To investigate this concern we estimate at what distance upwind of the BCO the sea salt particles would have been injected into the atmosphere to be measured near the top of the subcloud layer above the measurement site. Assuming that the upward motion of the sea salt particles is $0.2 \mathrm{~m} \mathrm{~s}^{-1}$ and the mean horizontal wind speed is $5.5 \mathrm{~m} \mathrm{~s}^{-1}$ (calculated from data used in Fig. 6d), the detected sea salt particles (neglecting their increasing mass), which occur at an altitude of $400 \mathrm{~m}$ above the BCO, would have left the water $11 \mathrm{~km}$ eastward (main wind direction). Even a lucky particle caught in an updraft that is 4 times more vigorous would still have originated well upwind of the surf zone at the shore break. This suggests that the observed particles have their origin well away from the surf zone and are representative of processes occurring over the open ocean.

All in all, by a process of elimination we are led to the conclusion that the observed haze echoes are real and caused by hygroscopically grown sea salt particles, which are injected from the sea surface into the atmosphere.

\section{Conclusions}

In this study, we show for the first time that highsensitivity radars can be used to detect hygroscopically grown sea salt particles in the trade wind region of the Atlantic Ocean. Two case studies and a statistical approach were used to quantify with remote sensing instruments the presence of large $(>500 \mathrm{~nm})$ sea salt particles in the boundary layer below shallow cumulus clouds. These hygroscopically grown sea salt particles appeared as a weak radar reflectivity signal $(-65$ to $-50 \mathrm{~dB} Z$ ) in the boundary layer with a major occurrence in the updraft region of shallow cumulus clouds. An increasing radar reflectivity signal toward the cloud base is caused by increasing relative humidity, which leads to a growing process of the sea salt particles. Caused by subsidence of dry air masses with a related change in the humidity profile, the weak radar reflectivity signal is less present in the downdraft regions in between the clouds.

By combining the Ka-band radar and Raman-lidar measurements, it is possible to retrieve size distributions of the hygroscopically grown sea salt particles in the subcloud layer. Our results show a good agreement with measurements from a dry-deposition sampler and an OPS instrument. For giant $\mathrm{CCN}$-sized particles $(D>$ $5 \mu \mathrm{m}$ ) the retrievals are rather insensitive to the assumed 
shape parameter. The assumption of the shape parameter does, however, strongly influences inferences as to what the measurements of the giant $\mathrm{CCN}$ portend for the concentration of $\mathrm{CCN}$ overall. Conservative estimates of the assumed shape parameter do, however, indicate that at wind speed characteristic of the maritime trades, CCN concentrations from sea salt production are likely greater than $20 \mathrm{~cm}^{-3}$ and much larger concentrations are difficult to rule out. While the size of the hygroscopically grown sea salt particles depends mainly on the environmental relative humidity conditions, the number concentration strongly depends on the horizontal wind speed at the sea surface. Higher wind speeds (larger than $4 \mathrm{~m} \mathrm{~s}^{-1}$ ) lead to more wave breaking at the sea surface, followed by a bubble-bursting process that injects more sea salt particles into the atmosphere.

A general conclusion is that hygroscopically grown sea salt particles are found to be frequent (in $76 \%$ of the measurements) and important in the trade wind region as sampled at the Barbados Cloud Observatory and can be readily detected with a high-sensitivity radar. In future studies, analyzing the hygroscopically grown sea salt particles in more detail will give a better understanding about

1) the vertical and temporal distribution of atmospheric sea salt particles in the trade wind region of the tropical Atlantic Ocean and

2) the sea salt aerosol-cloud interactions and how they influence precipitation processes.

Furthermore, we expect that other observatories close to the ocean and with similar instrumentation will detect these particles as well. These stations could be used to get an overview about the atmospheric distribution and cloud interaction processes of hygroscopically grown sea salt particles in different regions of Earth.

Acknowledgments. We thank Anna Luebke for her thoughtful comments and ideas during the developing process of this paper. Johannes Kiliani and Ilya Serikov provided the carefully analyzed Raman-lidar dataset. Akio Hansen delivered the Meteosat satellite pictures, which are based on a product from the Deutscher Wetterdienst (DWD), Referat Zentrale Entwicklung. Special thanks to Lutz Hirsch, Friedhelm Jansen, and Björn Brügmann, who have kept the Barbados Cloud Observatory running since 2010. The data are freely available to the broader community upon request. Scientific and technical support was given by Ulrich Pöschl, Meinrat O. Andreae, Joseph Prospero, Cassandra Gaston, Ovid O. Krüger, Thomas Klimach, Bettina Weber, David Farrell, Edmund Blades, Peter Sealy, and Maria Praß.
A. K. N. was supported by the Hans-Ertel Centre for Weather Research. This research network of universities, research institutes, and the Deutscher Wetterdienst is funded by the Federal Ministry of Transport and Digital Infrastructure (BMVI). V. G. was supported by the U.S. Department of Energy's (DOE) Atmospheric System Research (ASR), an Office of Science, Office of Biological and Environmental Research (BER) program, under Contract DE-AC02-06CH11357 awarded to Argonne National Laboratory, and NSF Grant AGS1445831 awarded to the University of Chicago. K. K. acknowledges support from the German Science Foundation (DFG; Grant KA 2280/2-1).

We thank three anonymous reviewers for their helpful suggestions and remarks.

\section{REFERENCES}

Acquistapace, C., S. Kneifel, U. Löhnert, P. Kollias, M. Maahn, and M. Bauer-Pfundstein, 2017: Optimizing observations of drizzle onset with millimeter-wavelength radars. Atmos. Meas. Tech., 10, 1783-1802, https://doi.org/10.5194/ amt-10-1783-2017.

Ault, A. P., and Coauthors, 2013: Size-dependent changes in sea spray aerosol composition and properties with different seawater conditions. Environ. Sci. Technol., 47, 5603-5612, https://doi.org/10.1021/es400416g.

Erickson, D. J., and R. A. Duce, 1988: On the global flux of atmospheric sea salt. J. Geophys. Res., 93, 14 079-14 088, https:// doi.org/10.1029/JC093iC11p14079.

Estillore, A. D., and Coauthors, 2017: Linking hygroscopicity and the surface microstructure of model inorganic salts, simple and complex carbohydrates, and authentic sea spray aerosol particles. Phys. Chem. Chem. Phys., 19, 21 101-21111, https://doi.org/10.1039/C7CP04051B.

Görsdorf, U., V. Lehmann, M. Bauer-Pfundstein, G. Peters, D. Vavriv, V. Vinogradov, and V. Volkov, 2015: A 35-GHz polarimetric Doppler radar for long-term observations of cloud parameters-Description of system and data processing. J. Atmos. Oceanic Technol., 32, 675-690, https://doi.org/ 10.1175/JTECH-D-14-00066.1.

Gossard, E. E., W. D. Neff, R. J. Zamora, and J. E. Gaynor, 1984: The fine structure of elevated refractive layers: Implications for over-the-horizon propagation and radar sounding systems. Radio Sci., 19, 1523-1533, https://doi.org/10.1029/ RS019i006p01523.

Haarig, M., A. Ansmann, J. Gasteiger, K. Kandler, D. Althausen, H. Baars, and D. A. Farrell, 2017: Dry versus wet marine particle optical properties: RH dependence of depolarization ratio, backscatter, and extinction from multiwavelength lidar measurements during SALTRACE. Atmos. Chem. Phys., 17, 14 199-14217, https://doi.org/10.5194/acp-17-14199-2017.

Jaeglé, L., P. K. Quinn, T. S. Bates, B. Alexander, and J.-T. Lin, 2011: Global distribution of sea salt aerosols: New constraints from in situ and remote sensing observations. Atmos. Chem. Phys., 11, 3137-3157, https://doi.org/10.5194/ acp-11-3137-2011.

Jensen, J. B., and A. D. Nugent, 2017: Condensational growth of drops formed on giant sea-salt aerosol particles. J. Atmos. Sci., 74, 679-697, https://doi.org/10.1175/JAS-D-15-0370.1. 
Johnson, D. B., 1982: The role of giant and ultragiant aerosol particles in warm rain initiation. J. Atmos. Sci., 39, 448-460, https://doi.org/ 10.1175/1520-0469(1982)039<0448:TROGAU >2.0.CO;2.

Kandler, K., and Coauthors, 2011: Electron microscopy of particles collected at Praia, Cape Verde, during the Saharan Mineral Dust Experiment: Particle chemistry, shape, mixing state and complex refractive index. Tellus, 63B, 475-496, https://doi.org/ 10.1111/j.1600-0889.2011.00550.x.

- , K. Schneiders, M. Ebert, M. Hartmann, S. Weinbruch, M. Prass, and C. Pöhlker, 2018: Composition and mixing state of atmospheric aerosols determined by electron microscopy: Method development and application to aged Saharan dust deposition in the Caribbean boundary layer. Atmos. Chem. Phys., 18, 13 429-13 455, https://doi.org/ 10.5194/acp-18-13429-2018.

Latham, J., and M. H. Smith, 1990: Effect on global warming of wind-dependent aerosol generation at the ocean surface. $\mathrm{Na}$ ture, 347, 372-373, https://doi.org/10.1038/347372a0.

LeMone, M. A., and W. T. Pennell, 1976: The relationship of trade wind cumulus distribution to subcloud layer fluxes and structure. Mon. Wea. Rev., 104, 524-539, https://doi.org/10.1175/ 1520-0493(1976)104<0524:TROTWC>2.0.CO;2.

Levin, Z., and W. R. Cotton, 2009: Aerosol Pollution Impact on Precipitation: A Scientific Review. Springer Netherlands, 386 pp., https://doi.org/10.1007/978-1-4020-8690-8.

Lewis, E., and S. Schwartz, 2004: Sea Salt Aerosol Production: Mechanisms, Methods, Measurements and Models. Geophys. Monogr., Vol. 152, Amer. Geophys. Union, 413 pp.

Medeiros, B., and L. Nuijens, 2016: Clouds at Barbados are representative of clouds across the trade wind regions in observations and climate models. Proc. Natl. Acad. Sci. USA, 113, E3062-E3070, https://doi.org/10.1073/pnas.1521494113.

Mordy, W., 1959: Computations of the growth by condensation of a population of cloud droplets. Tellus, 11, 16-44, https://doi.org/ 10.3402/tellusa.v11i1.9283.

Morris, H. S., A. D. Estillore, O. Laskina, V. H. Grassian, and A. V. Tivanski, 2016: Quantifying the hygroscopic growth of individual submicrometer particles with atomic force microscopy. Anal. Chem., 88, 3647-3654, https://doi.org/10.1021/ acs.analchem.5b04349.

Naumann, A. K., and A. Seifert, 2016: Recirculation and growth of raindrops in simulated shallow cumulus. J. Adv. Model. Earth Syst., 8, 520-537, https://doi.org/10.1002/2016MS000631.

Noll, K. E., and K. Y. Fang, 1989: Development of a dry deposition model for atmospheric coarse particles. Atmos. Environ., 23, 585-594, https://doi.org/10.1016/0004-6981(89)90007-3.

Nuijens, L., B. Stevens, and A. P. Siebesma, 2009: The environment of precipitating shallow cumulus convection. J. Atmos. Sci., 66, 1962-1979, https://doi.org/10.1175/2008JAS2841.1.

- B. Medeiros, I. Sandu, and M. Ahlgrimm, 2015: The behavior of trade-wind cloudiness in observations and models: The major cloud components and their variability. J. $A d v$. Model. Earth Syst., 7, 600-616, https://doi.org/10.1002/ 2014MS000390.

O'Connor, E. J., R. J. Hogan, and A. J. Illingworth, 2005: Retrieving stratocumulus drizzle parameters using Doppler radar and lidar. J. Appl. Meteor., 44, 14-27, https://doi.org/10.1175/ JAM-2181.1.

_ - A. J. Illingworth, I. M. Brooks, C. D. Westbrook, R. J. Hogan, F. Davies, and B. J. Brooks, 2010: A method for estimating the turbulent kinetic energy dissipation rate from a vertically pointing Doppler lidar, and independent evaluation from balloon-borne in situ measurements. J. Atmos.
Oceanic Technol., 27, 1652-1664, https://doi.org/10.1175/ 2010JTECHA1455.1.

O'Dowd, C. D., and G. de Leeuw, 2007: Marine aerosol production: A review of the current knowledge. Philos. Trans. Roy. Soc. London, 365A, 1753-1774, https://doi.org/10.1098/ rsta.2007.2043.

Ott, D. K., and T. M. Peters, 2008: A shelter to protect a passive sampler for coarse particulate matter, $\mathrm{PM}_{10-2.5}$. Aerosol Sci. Technol., 42, 299-309, https://doi.org/10.1080/ 02786820802054236.

Ovadnevaite, J., D. Ceburnis, M. Canagaratna, H. Berresheim, J. Bialek, G. Martucci, D. R. Worsnop, and C. O'Dowd, 2012: On the effect of wind speed on submicron sea salt mass concentrations and source fluxes. J. Geophys. Res., 117, D16201, https://doi.org/10.1029/2011JD017379.

Petters, M. D., and S. M. Kreidenweis, 2007: A single parameter representation of hygroscopic growth and cloud condensation nucleus activity. Atmos. Chem. Phys., 7, 1961-1971, https://doi.org/10.5194/acp-7-1961-2007.

Posselt, R., and U. Lohmann, 2008: Influence of giant CCN on warm rain processes in the ECHAM5 GCM. Atmos. Chem. Phys., 8, 3769-3788, https://doi.org/10.5194/acp-8-3769-2008.

Prather, K. A., and Coauthors, 2013: Bringing the ocean into the laboratory to probe the chemical complexity of sea spray aerosol. Proc. Natl. Acad. Sci. USA, 110, 7550-7555, https:// doi.org/10.1073/pnas.1300262110.

Prospero, J. M., and O. L. Mayol-Bracero, 2013: Understanding the transport and impact of African dust on the Caribbean basin. Bull. Amer. Meteor. Soc., 94,1329-1337, https://doi.org/10.1175/ BAMS-D-12-00142.1.

_ F. Follard, J. Molinié, and A. Jeannot, 2014: Characterizing the annual cycle of African dust transport to the Caribbean basin and South America and its impact on the environment and air quality. Global Biogeochem. Cycles, 28, 757-773, https://doi.org/10.1002/2013GB004802.

Pruppacher, H., and J. Klett, 2010: Microphysics of Clouds and Precipitation. Springer, $954 \mathrm{pp}$.

Quinn, P. K., D. B. Collins, V. H. Grassian, K. A. Prather, and T. S. Bates, 2015: Chemistry and related properties of freshly emitted sea spray aerosol. Chem. Rev., 115, 4383-4399, https:// doi.org/10.1021/cr500713g.

Rauber, R. M., and Coauthors, 2007: Rain in shallow cumulus over the ocean: The RICO campaign. Bull. Amer. Meteor. Soc., 88, 1912-1928, https://doi.org/10.1175/BAMS-88-12-1912.

Rudich, Y., O. Khersonsky, and D. Rosenfeld, 2002: Treating clouds with a grain of salt. Geophys. Res. Lett., 29, 2060, https:// doi.org/10.1029/2002GL016055.

Satheesh, S. K., and D. Lubin, 2003: Short wave versus long wave radiative forcing by Indian Ocean aerosols: Role of seasurface winds. Geophys. Res. Lett., 30, 1695, https://doi.org/ 10.1029/2003GL017499.

_ , and K. K. Moorthy, 2005: Radiative effects of natural aerosols: A review. Atmos. Environ., 39, 2089-2110, https://doi.org/ 10.1016/j.atmosenv.2004.12.029.

Stevens, B., and Coauthors, 2016: The Barbados Cloud Observatory: Anchoring investigations of clouds and circulation on the edge of the ITCZ. Bull. Amer. Meteor. Soc., 97, 787-801, https://doi.org/10.1175/BAMS-D-14-00247.1.

Takemura, T., T. Nakajima, O. Dubovik, B. N. Holben, and S. Kinne, 2002: Single-scattering albedo and radiative forcing of various aerosol species with a global three-dimensional model. J. Climate, 15, 333-352, https://doi.org/10.1175/ 1520-0442(2002)015<0333:SSAARF>2.0.CO;2. 
Tang, I. N., A. C. Tridico, and K. H. Fung, 1997: Thermodynamic and optical properties of sea salt aerosols. J. Geophys. Res., 102, 23 269-23 275, https://doi.org/10.1029/97JD01806.

Testud, J., S. Oury, R. A. Black, P. Amayenc, and X. Dou, 2001: The concept of "normalized" distribution to describe raindrop spectra: A tool for cloud physics and cloud remote sensing. J. Appl. Meteor., 40, 1118-1140, https://doi.org/10.1175/ 1520-0450(2001)040<1118:TCONDT>2.0.CO;2.

Weinzierl, B., and Coauthors, 2017: The Saharan Aerosol LongRange Transport and Aerosol-Cloud-Interaction Experiment: Overview and selected highlights. Bull. Amer. Meteor.
Soc., 98, 1427-1451, https://doi.org/10.1175/BAMS-D-1500142.1.

Wex, H., and Coauthors, 2016: Aerosol arriving on the Caribbean island of Barbados: Physical properties and origin. Atmos. Chem. Phys., 16, 14 107-14 130, https://doi.org/10.5194/acp-16-14107-2016.

Wood, N., 1981: A simple method for the calculation of turbulent deposition to smooth and rough surfaces. J. Aerosol Sci., 12, 275-290, https://doi.org/10.1016/0021-8502(81)90127-0.

Woodcock, A. H., 1952: Atmospheric salt particles and raindrops. J. Meteor., 9, 200-212, https://doi.org/10.1175/15200469(1952)009<0200:ASPAR>2.0.CO;2. 